\title{
Marine Environment Influence on Fiber Optic Systems Operation
}

\author{
Bekir Novkinića, Igor Vujovićb, Joško Šoda
}

Optic communications are increasingly used in many areas, including traffic and maritime nowadays. There is a lack of researches about environmental parameters impact to the operation of fibers in traffic systems, i.e. ships, cars, aircraft or port logistics. This paper investigates environmental influence on three-layer fiber optic system. The two-layer optic system is also analyzed for the comparison purposes. Several environmental factors were simulated, including temperature, pressure, and humidity for all three IR windows. In the three layer optic system, the environmental influence is brought through the air's refractivity index. The final goal is to determine if the change of the environmental factor(s) can change or lose some of the modes used for communication in some specific application.

\section{KEY WORDS}

$\sim$ Refractive index

$\sim$ Fiber optic

$\sim$ Ciddor equation a. Ministry of Defence, Banja Luka, Bosnia and Herzegovina

e-mail: bekir_novkinic@hotmail.com

b. University of Split, Faculty of Maritime Studies, Split, Croatia e-mail: ivujovic@pfst.hr

\section{INTRODUCTION}

The navy's interest in secure communications was responsible for optical communication implementation aboard vessels (war ships).

The marine environment is of special interest, due to a huge traffic and trade made over oceans and seas (Review of Maritime Transport 2013, 2013). It is also of interest to the navies all over the world. As known, the marine environment is not favorable for many materials and equipment. An increased salinity causes many problems, and corrosion is the most prominent one (Slamova et al., 2012). Salinity is increased not just aboard ships, but also in coastal areas. ISO classification (ISO 9225, 1992) of pollution by airborne salinity (Unknown, 2002; Airborne Salinity, 2015) represented by sodium chloride deposition rate in annual average is categorized by four categories: $\mathrm{S}_{0^{\prime}} \mathrm{S}_{1}, \mathrm{~S}_{2}$ and $\mathrm{S}_{3}$. Category $\mathrm{S}_{0}$ refers to non-coastal areas, where $\mathrm{NaCl}$ deposition is less than $3 \mathrm{mg} / \mathrm{m}^{2} /$ day. Category $\mathrm{S}_{1}$ refers to coastal areas, where $\mathrm{NaCl}$ deposition is between 3 and $60 \mathrm{mg} / \mathrm{m}^{2} /$ day. Category $S_{2}$ refers to the coastal environment, where $\mathrm{NaCl}$ deposition is between 60 and $300 \mathrm{mg} / \mathrm{m}^{2} /$ day. Category $\mathrm{S}_{3}$ refers to coastal areas within 200 meters from the sea, where $\mathrm{NaCl}$ deposition is between 300 and $1500 \mathrm{mg} / \mathrm{m}^{2} /$ day. Airborne salinity is present in so called seaspray, which consists of marine organic aerosol, salt, and other components, which are pushed from the sea to land or ships over the air (Gant and Meskhidze, 2013).

In this paper, environmental influence was incorporated by the change in the refractive index. Refractive index was researched for air-ocean interface (Frederickson, 2000; Jin and Stamnes, 1994; Friehe et al., 1975; Thayer, 1974), but this is not 
exactly the scope of this paper. We are not interested in the refractive index of sunlight at the interface, but in optic fibers, which are usually not at the direct sunlight.

The research in refractive index variations started in the second half of the 20th century (Edlen, 1953; Edlen, 1966; Waxler and Cleek, 1971; Waxler and Cleek, 1973). Researches have been slowing down and almost stopped. It is probably due to a lack of practical interest in the matter. When micro optical fibers appear, the problem has risen again due to the possibility that the environment influences the signal guidance in optic communications (Galindez et al., 2012; Leviton and Frey, 2006; Gupta et al., 1998).

When dealing with optical microfiber, consisting of the untapered ends, tapers, and micrometer-diameter waist, the light is first guided in a standard manner through the core in the untapered part. However, taper regions are problematic, because at some point, the guidance is actually not by the core-cladding interface, but by the cladding-surrounding. The surrounding is usually air, liquids or special coating. The surrounding has the refractive index lower than the cladding. When this happens, due to a small diameter of the core, the core can be neglected and the two-layer model can be used again, bur for cladding-surrounding (Karapetyan, 2011).

The fist proposed solution for the three-layer structure was given in (Belanov, 1976), which is repeated in (Monerie, 1982). The solution corresponded only for the weakly guiding fibers, which have linearly polarized modes. An attempt to obtain the solution for the HE/EH, TE and TM modes was proposed in (Tsao et al., 1989). The solution for cladding modes was published in (Erdogan, 1997). The first full solution of the problem was proposed in (Zhang and Shi, 2005).

This paper is organized as follows. The second chapter deals with possible environmental parameters that could lead to refractivity factor change, and, consequently, to failure in light wave guidance. A special subsection presents a mathematical model for the evaluation of the environmental parameters. The third chapter presents the results of numerical experiments. Finally, conclusions are presented.

\section{INVESTIGATION OF INFLUENTIAL FACTORS}

The refractive index plays a vital role in light guidance. It determines energy loss and modes of propagation. If the refractive index changes, the reflection from the cladding is changed to another angle. In dramatic cases, total reflection cannot be established and communication is terminated. Energy balance and efficiency is influenced as well. A change in the refractive index can affect reliability of information delivery, change mode, etc.

The refractive index is related to the relative dielectric constant (Kaiser et al., 2010; Helhel et al., 2007; Kasap, 2006;
Silans et al., 2009; Vujović et al., 2014a; Vujović et al., 2014b; Kulenović et al., 2014), which is reported to be dependent on moisture or humidity, frequency and temperature. Hence, an indirect method to research environmental impact on refractive index is to follow changes in the relative dielectric constant. Due to temperature dependence, it should be clear that it is not the same if the installation is under water line or somewhere at direct sunlight. At the sunlight, the installation can be warmed up to relatively high temperatures. The question is how and when such change in temperature can lead to communication system failure. It should also be noted that optic materials are also dielectric materials. In the IR range (optic communication range) two types of polarization exist - ionic and electronic, which is not the simplest mathematical model.

\subsection{Ciddor equation implementation}

The greatest advance in the field of the air refractive index was achieved by (Ciddor, 1996). It is of interest to the problem addressed in this paper, because one of possible surroundings can be air. Research should be different for different materials in a way of index's range. In the case of air, the range can be determined by the Ciddor equation. In the case of a different material, the range can be determined by some other means. The main manifold of this equation is that it does not include the sea salt explicitly into calculus.

The first step in Ciddor equation calculation is to express input parameters in needed units. The first input parameter is wavelength in vacuum in nanometers. In the case of fiber optic communications, there are three windows: $850 \mathrm{~nm}, 1300 \mathrm{~nm}$ and $1550 \mathrm{~nm}$. The second parameter is temperature in degrees Celsius. The standard temperature, denoted as $t$, is 20 degrees. The third parameter is air pressure in Pascals. The standard pressure $(p)$ is 101.325 $\mathrm{Pa}$. The forth input parameter is relative humidity $(\mathrm{RH})$ in percentages. The standard $\mathrm{RH}$ is $50 \%$. This parameter is easier to input to the computer program as percentage. However, the computer should recalculate this parameter as mole fraction. The fifth input parameter is the concentration of carbon dioxide $\left(\mathrm{CO}_{2}\right)$ in micromoles per mol of parts per million (ppm). The recommended concentration is $450 \mu \mathrm{mol} / \mathrm{mol}$. $\mathrm{CO}_{2}$ is in equation input as $\mathrm{x}_{\mathrm{CO} 2}$. Inputs are many constants as shown further.

In order to prepare humidity for Ciddor, enhancement factor, $f$, of water vapor in air at temperature $T$, should be calculated (Ciddor, 1996) using $a=1.00062, \beta=3.14 \cdot 10^{-8} \mathrm{~Pa}^{-1}$, and $Y=5.6 \cdot 10^{-7}{ }^{\circ} \mathrm{C}^{-2}$ :

$$
f(p, t)=a+\beta \cdot p+\gamma \cdot t^{2}
$$


If the $\mathrm{RH}$ is in percentage, than the $\mathrm{RH}$ parameter can be introduced through mole fraction of wave vapor in moist air (Stone and Zimmerman, 2004a):

$x_{v}=\frac{R H}{100} \cdot f(p, t) \cdot \frac{p_{s v}(t)}{p}$

Pressure $p_{s v}$ can be calculated by example code in Matlab (Matlab code 1):

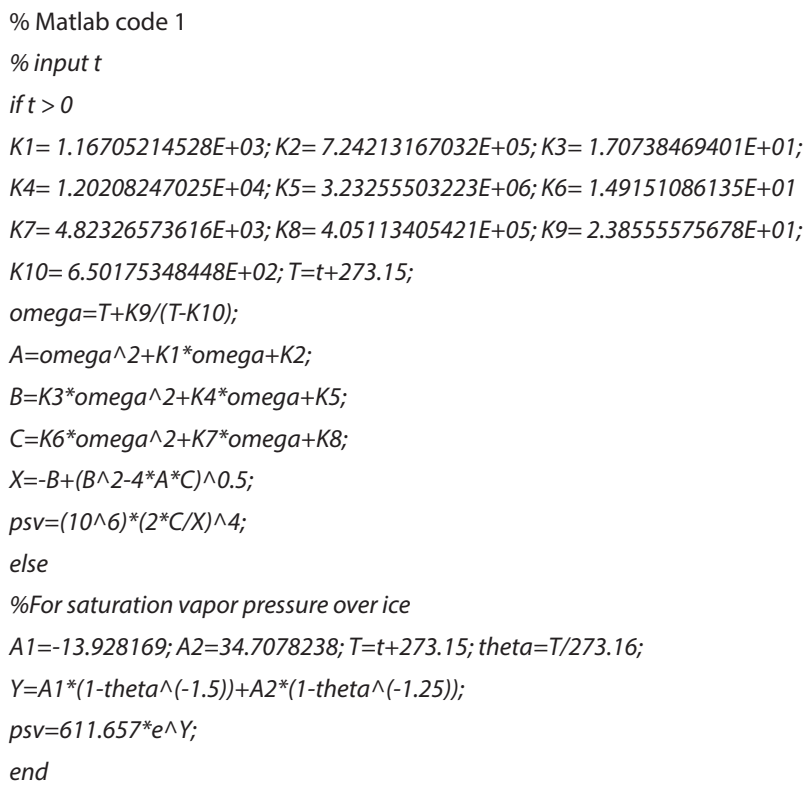

For the following step, several constants should be included:

$\mathrm{w}_{0}=295.235 \mu \mathrm{m}^{-2}$,

$\mathrm{w}_{1}=2.6422 \mu \mathrm{m}^{-2}$,

$\mathrm{w}_{2}=-0.03238 \mu \mathrm{m}^{-4}$,

$\mathrm{w}_{3}=0.004028 \mu \mathrm{m}^{-6}$,

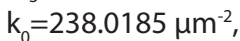

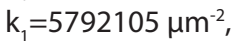

$\mathrm{k}_{2}=57.362 \mu \mathrm{m}^{-2}$,

$\mathrm{k}_{3}=167917 \mu \mathrm{m}^{-2}$,

$\mathrm{a}_{0}=1.58123 \cdot 10^{-6} \mathrm{~K} \cdot \mathrm{Pa}^{-1}$,

$\mathrm{a}_{1}=-2.9331 \cdot 10^{-8} \mathrm{~Pa}^{-1}$,

$\mathrm{a}_{2}=1.1043 \cdot 10^{-10} \mathrm{~K}^{-1} \mathrm{~Pa}^{-1}$,

$\mathrm{b}_{0}=5.707 \cdot 10^{-6} \mathrm{~K} \cdot \mathrm{Pa}^{-1}$,

$\mathrm{b}_{1}=-2.051 \cdot 10^{-8} \mathrm{~Pa}^{-1}$,

$\mathrm{c}_{0}=1.83 \cdot 10^{-11} \mathrm{~K} \cdot \mathrm{Pa}^{-1}$,

$\mathrm{c}_{1}=-2.376 \cdot 10^{-6} \mathrm{~Pa}^{-1}$,

$\mathrm{d}=1.83 \cdot 10^{-11} \mathrm{~K}^{2} \mathrm{~Pa}^{-2}$,

$\mathrm{e}=-0.765 \cdot 10^{-8} \mathrm{~K}^{2} \mathrm{~Pa}^{-2}$,

$\mathrm{p}_{\mathrm{r} 1}=101325 \mathrm{~Pa}$,

$\mathrm{t}_{\mathrm{r} 1}=288.15 \mathrm{~K}$, compressibility of dry air $z_{a}=0.9995922115$ (does not have unit, because it is a ratio),

$\rho_{\mathrm{vs}}=0.00985938 \mathrm{~kg} / \mathrm{m}^{3}$,

gas constant is $r=8.314472 \mathrm{~J} \mathrm{~mol}^{-1} \mathrm{~K}^{-1}$,

$m_{\mathrm{v}}=0.018015 \mathrm{~kg} / \mathrm{mol}$,

$s=1 / \lambda$.

Following equations should be programmed to calculate the refractive index of air. The first calculation is to determine intermediate results, gas constants corrections, which depends on s:

$r_{a s}=\left(\frac{k_{1}}{k_{0}-s}+\frac{k_{3}}{k_{2}-s}\right) \cdot 10^{-8}$

$r_{v s}=1.022 \cdot 10^{-8} \cdot\left(w_{0}+w_{1} \cdot s+w_{2} \cdot s^{2}+w_{3} \cdot s^{3}\right)$

The molar mass of dry air containing $\mathrm{x}_{\mathrm{c} 02} \mathrm{ppm}$ of $\mathrm{CO}_{2}$ in $\mathrm{kg} / \mathrm{mol}$ is expressed with:

$m_{a}=0.0289635+1.2011 \cdot 10^{-8} \cdot\left(x_{c o 2}-400\right)$

The inclusion of $\mathrm{CO}_{2}$ concentration is through expression:

$r_{a k s}=r_{a s} \cdot\left(1+5.34 \cdot 10^{-7} \cdot\left(x_{c o 2}-450\right)\right)$

and temperature should be substituted with absolute temperature:

$T=t+273.15$ 
The compressibility of moist air under the considered conditions is:

$$
\begin{aligned}
z_{m} & =1-\left(\frac{\rho}{T}\right) \cdot\left(a_{0}+a_{1} \cdot t+a_{2} \cdot t^{2}+\left(b_{0}+b_{1} \cdot t\right) \cdot x_{v}\right. \\
& \left.=>+\left(c_{0}+c_{1} \cdot t\right) \cdot x^{2}{ }_{v}\right)+\left(\frac{p}{T}\right) 2 \cdot\left(d+e \cdot x^{2}{ }_{v}\right)
\end{aligned}
$$

Density components are found with the following equations:

$\rho_{a k s}=\mathrm{p}_{r 1} \cdot \frac{m_{\mathrm{a}}}{z_{\mathrm{a}} \cdot r \cdot t_{r 1}}$

The density of the water vapor component is calculated with expression:

$\rho_{v}=\frac{x_{v} \cdot p \cdot m_{v}}{z_{m} \cdot r \cdot T}$

The density of the dry component of the moist air can be programmed as:

$\rho_{a}=\left(1-x_{v}\right) \cdot p \cdot \frac{m_{a}}{z_{m} \cdot r \cdot T}$

Finally, we obtain the refractive index of air:

$\mathrm{n}_{\mathrm{air}}=1+\frac{\rho_{\mathrm{a}}}{\rho_{a k s}} \cdot r_{a k s}+\frac{\rho_{\mathrm{v}}}{\rho_{v s}} r_{v s}$
This is implemented in i.e. Engineering Metrology Toolbox (Stone and Zimmerman, 2004a). Everybody can check the obtained results in the Results section using the calculator (Stone and Zimmerman, 2004b).

\section{NUMERICAL EXPERIMENTS AND RESULTS}

A great tool for the analysis of the refractive index is Optical Fibre Toolbox in Matlab (Karapetyan, 2011). A set of function can make Matlab realization of simulations and numerical experiments easier.

The final goal of the research should be the conclusion about the change in output constellation due to environmental factors. It is usual to consider that the air's refractive index $\left(n_{\text {air }}\right)$ is equal to 1 . In some cases a more precise number is used -1.000293 . This number corresponds to the standard conditions. Our goal is to vary nair and simulate environmental influence on signal propagation. In other words, how much change in refractive index is tolerable to reliably receive correct constellation.

An important question is how to integrate environmental effects to the three-layer model. It is certain that air characteristics are changed, including temperature and moisture or even salinity. Therefore, the refractive index of air is changing. However, it is not sure what with cladding. The temperature of air is transferred by heat transfer mechanism to cladding, but air temperature and cladding temperature are not the same. Salt can penetrate cladding, but in a nonlinear manner. It is also true for moisture. The problem also lies in the penetration depth through the core, because usual guidance total reflection is in core-cladding interface. It can be predicted that non-linear model for all dependences should be incorporated in the simulation of the influences.

Since the inclusion of all parameters requires the unknown nonlinear multispace model, we analyzed influential parameters separately.

Firstly, we will analyze the refractive index change due to a temperature difference between the standard and the simulated condition. This numerical experiment is for the standard, twolayer fiber optic model. Since the refractive index is different for various materials, we will use silica as an example material. Light wavelength is taken for three windows used in optic communications: 850,1300 , and $1550 \mathrm{~nm}$. Since the expected result is the change of the refractive index, it can be concluded that the wavelength of the reflected light and the propagation speed could be changed. Therefore we simulated also $\pm 50 \mathrm{~nm}$ as upper and lower border of the wavelength variation. Simulation results are shown in Figures 1 and 2. Figure 1 shows comparison of communication windows. Figure 2 shows the trend that the refractive index decreases with increase in wavelength. 


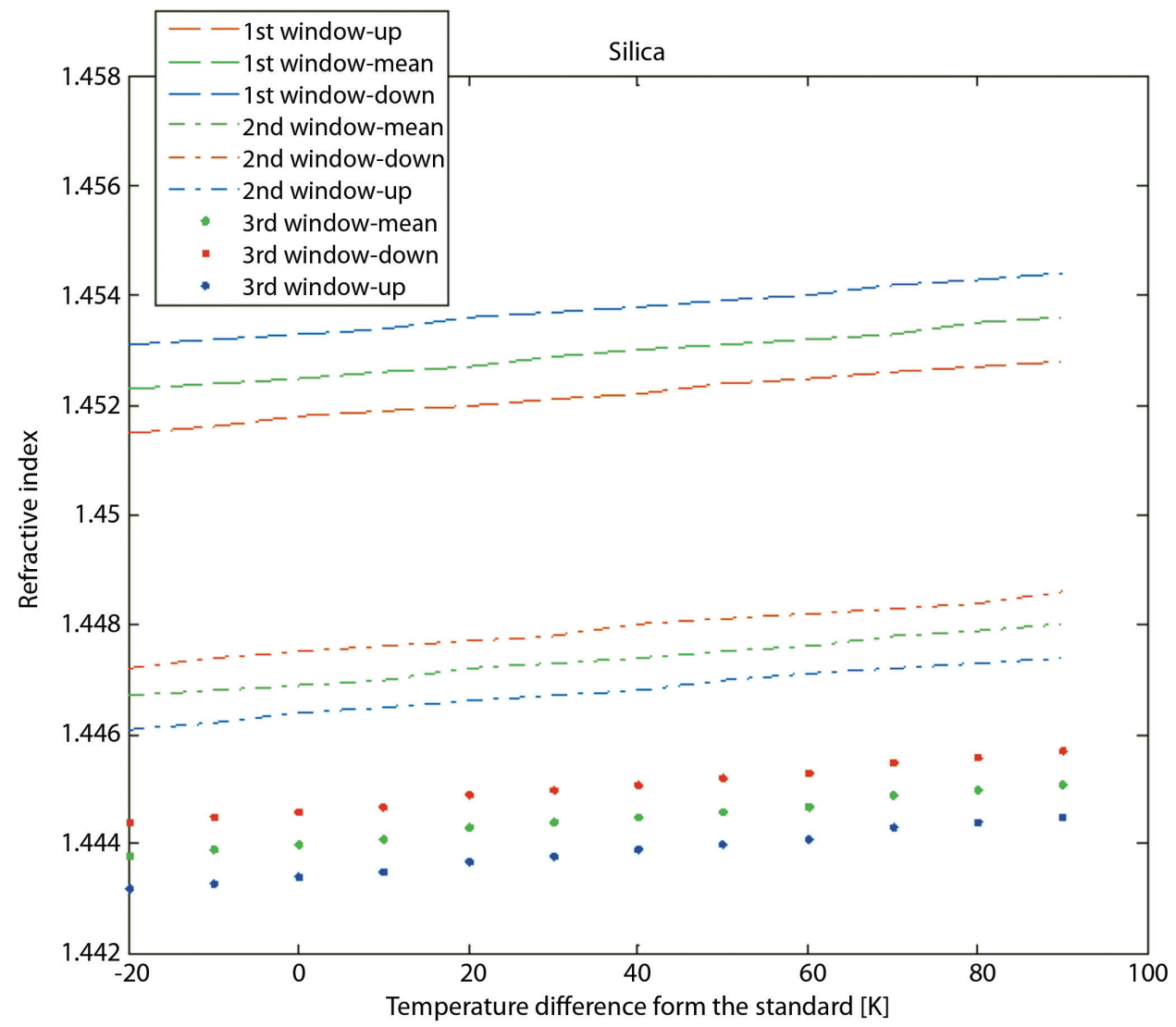

Figure 1.

Variation of the silica's refractive index due to a temperature deviation from the standard temperature for 850 (1st window), 1300 (2nd window) and 1550 (3rd window) $\pm 50 \mathrm{~nm}$ (upper and lower margine).

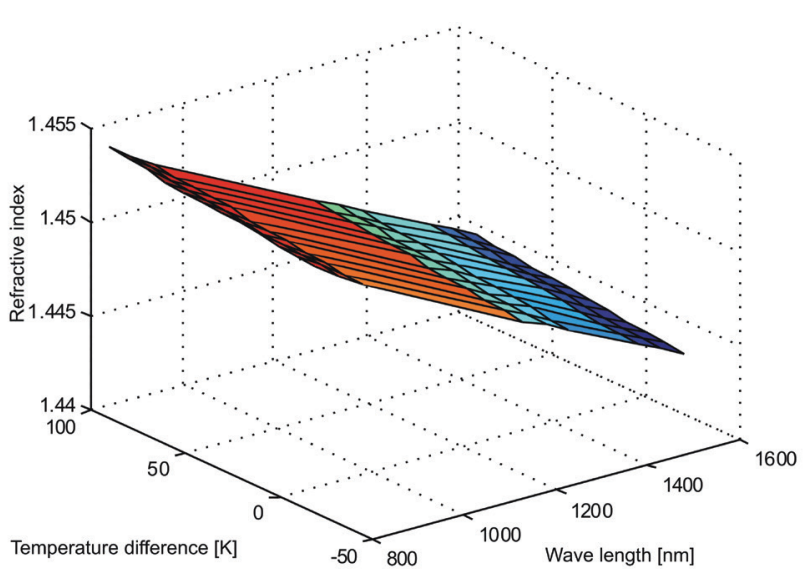

Figure 2.

3D plot of the wavelength - temperature - refractive index dependance.
Figure 3 shows that an increase in air pressure results in an increase of the refractive index for 850 and $1550 \mathrm{~nm}$. We can see indications of the saturation for $1300 \mathrm{~nm}$. The uncertainty of calculation is minimal at the standard air pressure of $101.325 \mathrm{kPa}$ (Figure 4).

Figure 5 shows that the increase of temperature decreases refractive index. The uncertainty of this calculation is the lowest around 15 and 20 degrees Celsius (Figure 6).

Figure 7 shows that refractive index decreases with the increase of relative humidity. The uncertainty of this calculation is the lowest in the case of dry air. A higher humidity results in a higher uncertainty (Figure 8 ). It should also be noted that the relative humidity over $85 \%$ results in potential formation of water droplets in the air. These droplets can be fatal for mariners.

Figure 9 shows that the refractive index is not dependent on $\mathrm{CO}_{2}$ concentration except for $1550 \mathrm{~nm}$. Figure 10 shows that uncertainty is constant for all $\mathrm{CO}_{2}$ concentrations. 


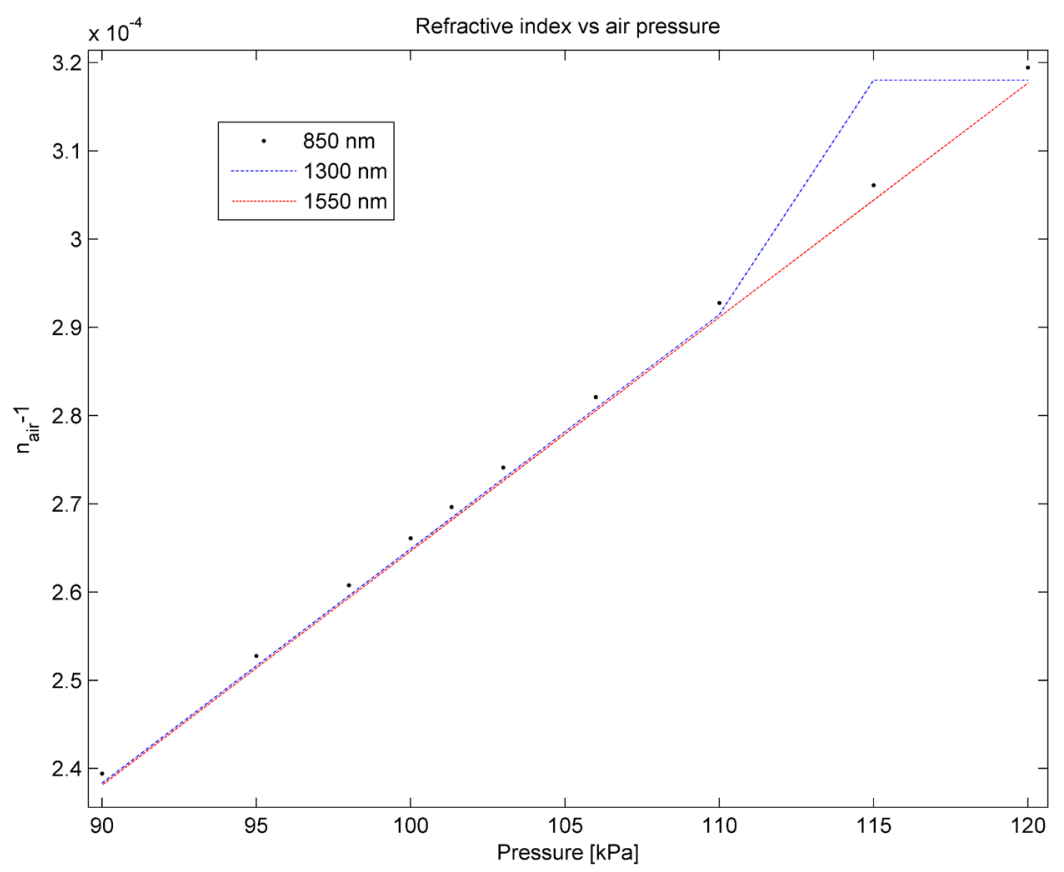

Figure 3.

Refractive index of air dependance on air pressure.

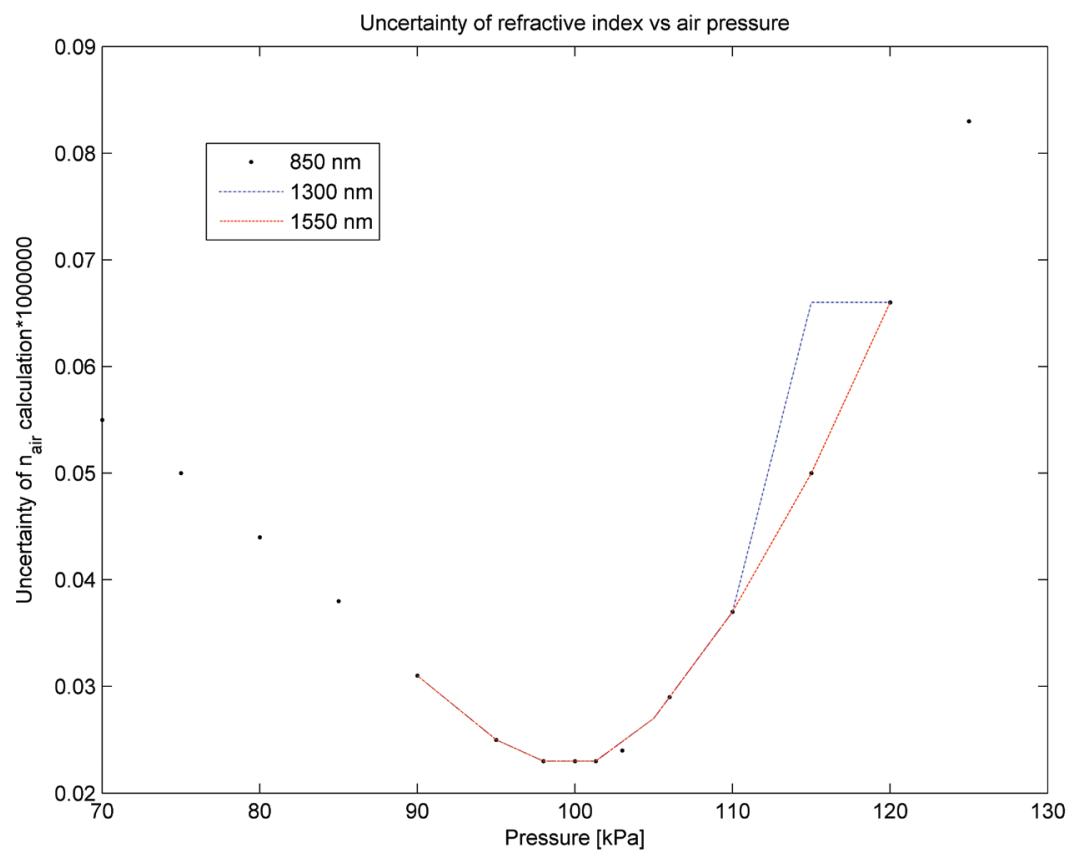

Figure 4.

Uncertainty of calcuation of the refractive index of air dependance on air pressure. 


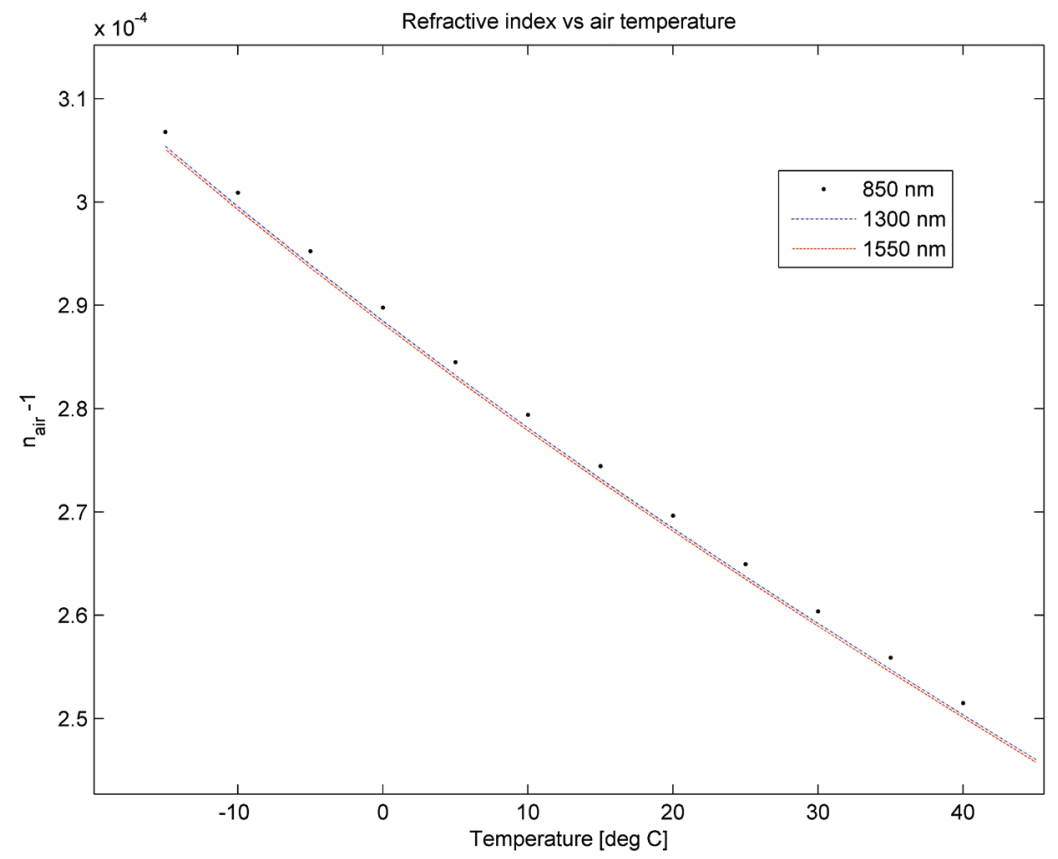

Figure 5.

Refractive index of air dependance on temperature.

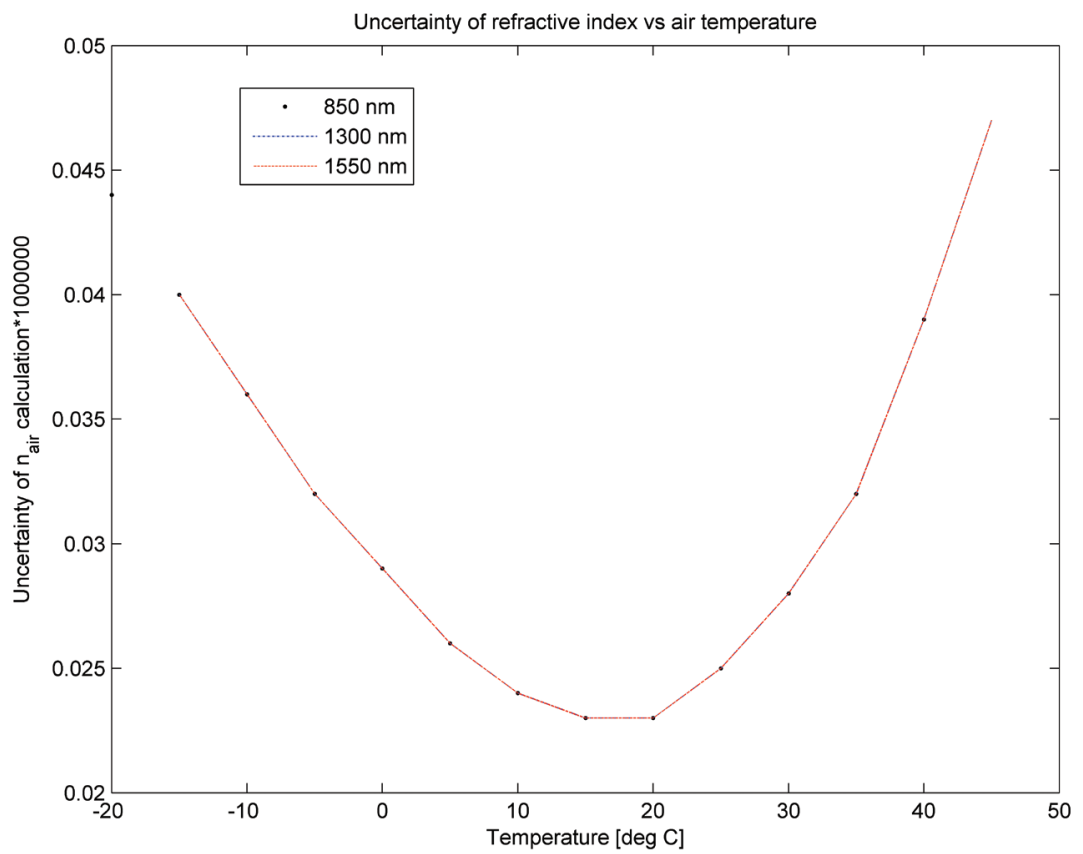

Figure 6.

Uncertainty of calcuation of the refractive index of air dependance on temperature. 


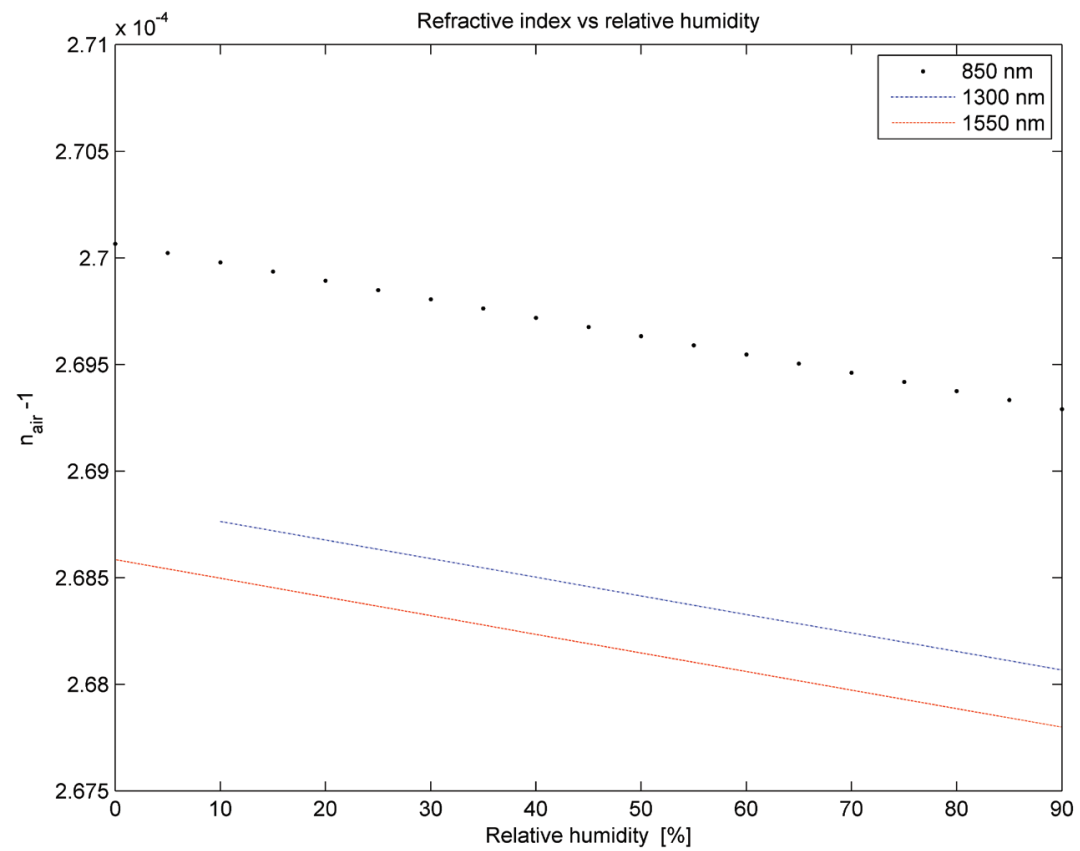

Figure 7.

Refractive index of air dependance on relative humidity.

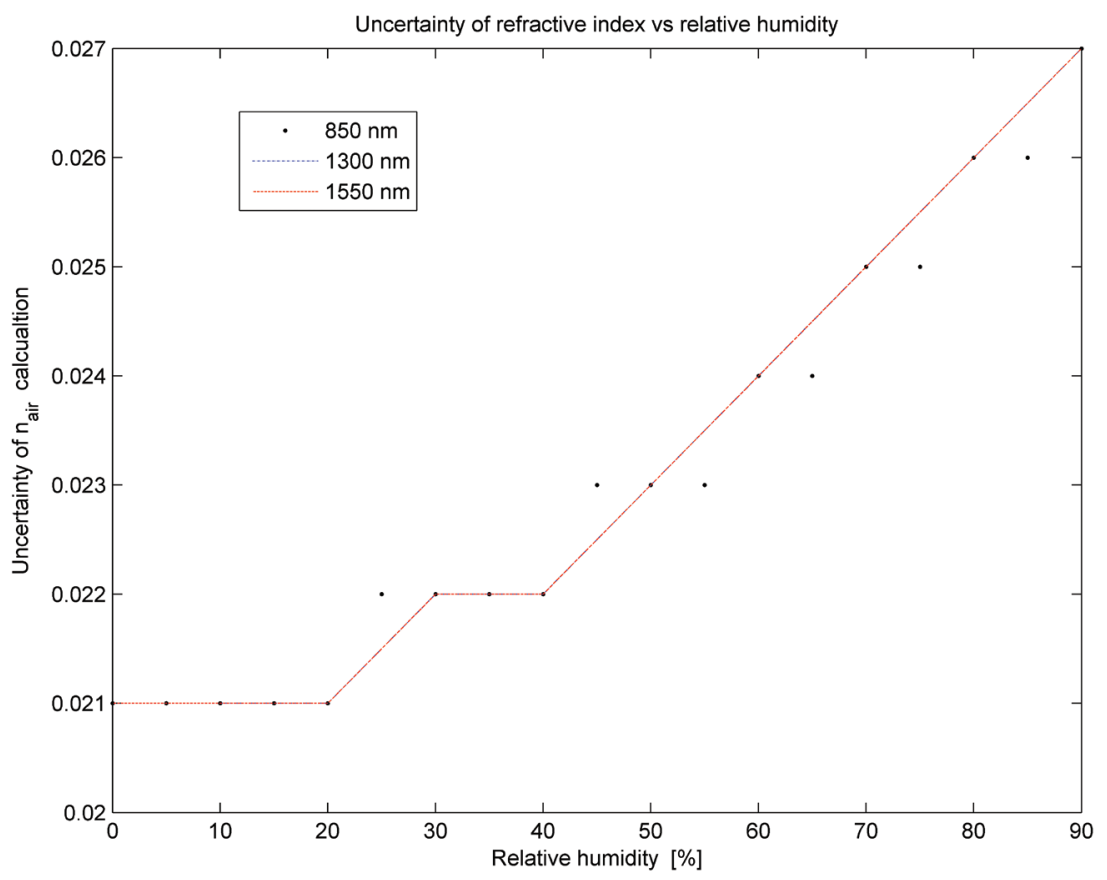

Figure 8.

Uncertainty of calcuation of the refractive index of air dependance on relative humidity. 


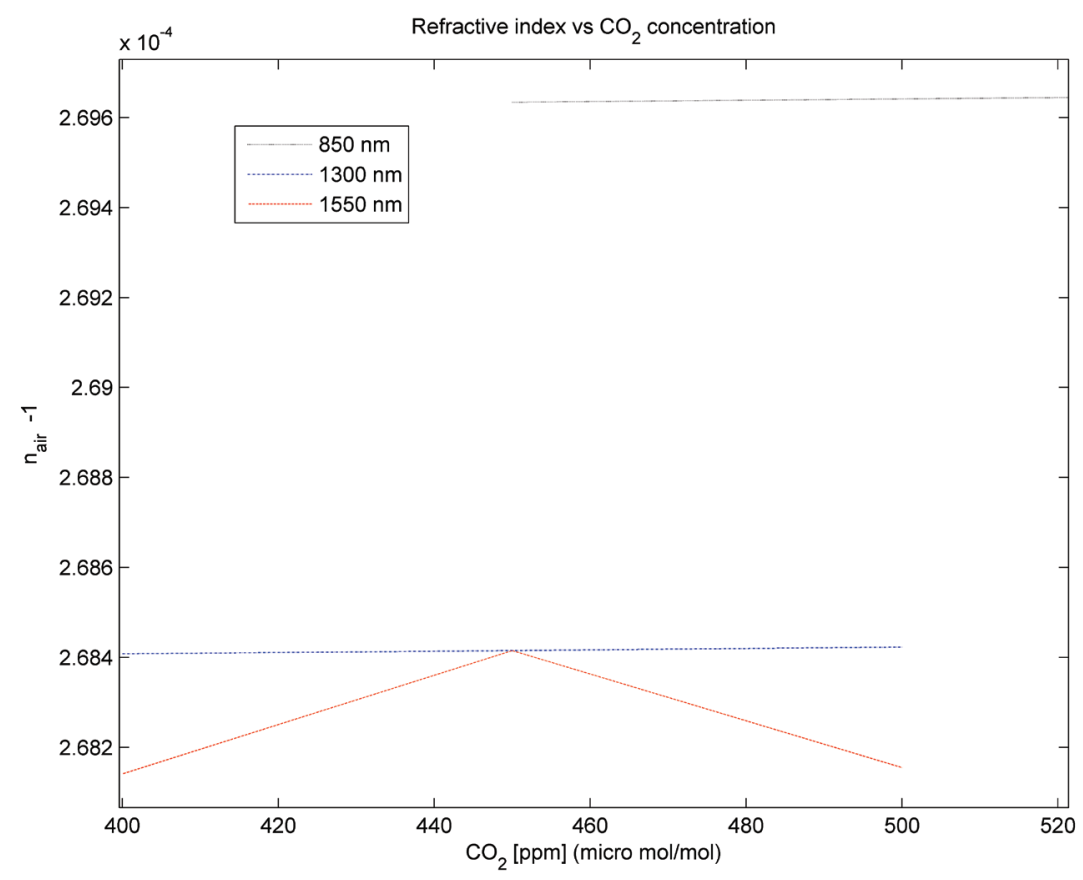

Figure 9.

Refractive index of air dependance on $\mathrm{CO}_{2}$ concentration.

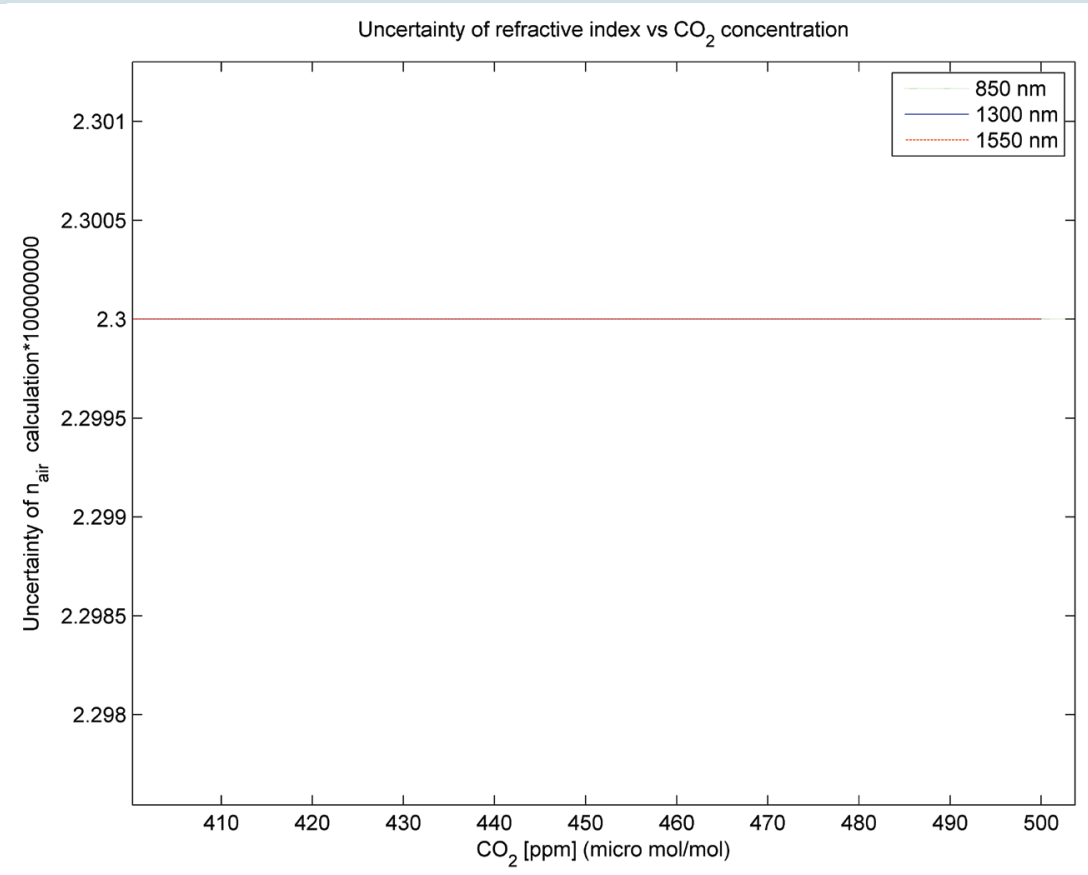

Figure 10.

Uncertainty of calcuation of the refractive index of air dependance on $\mathrm{CO}_{2}$ concentration. 


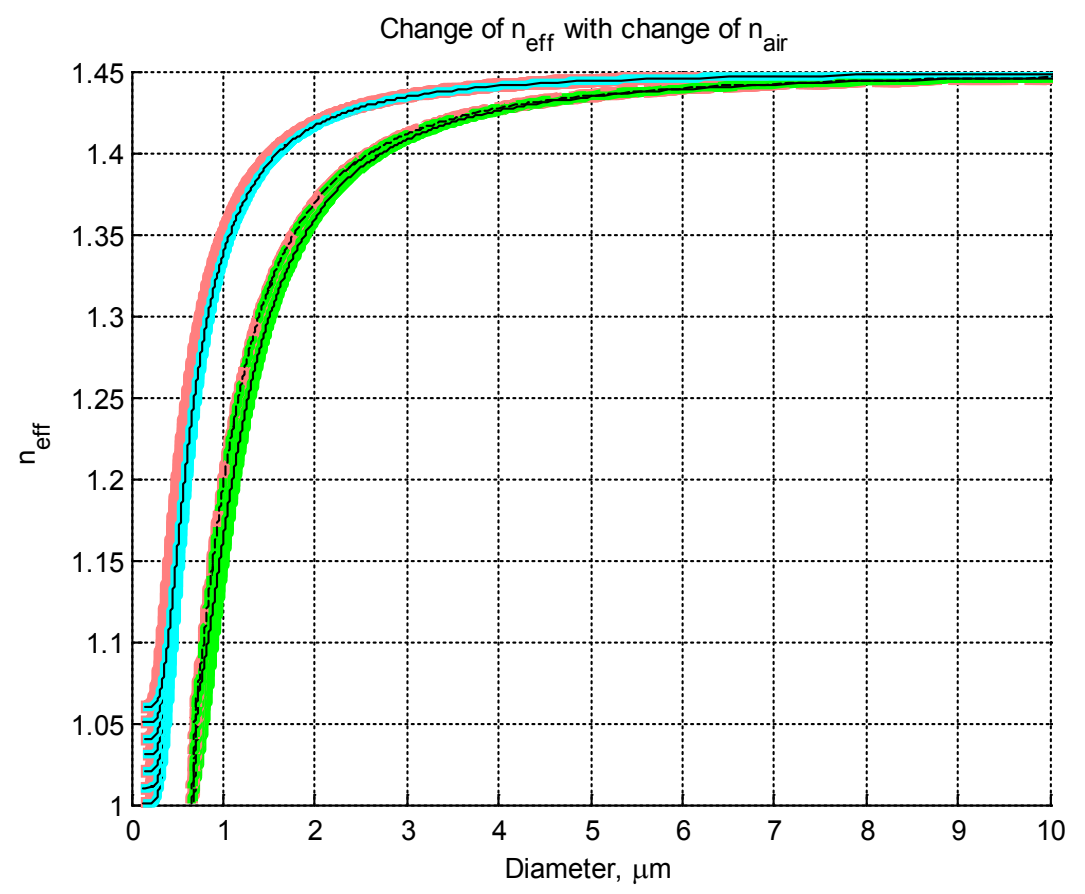

a)

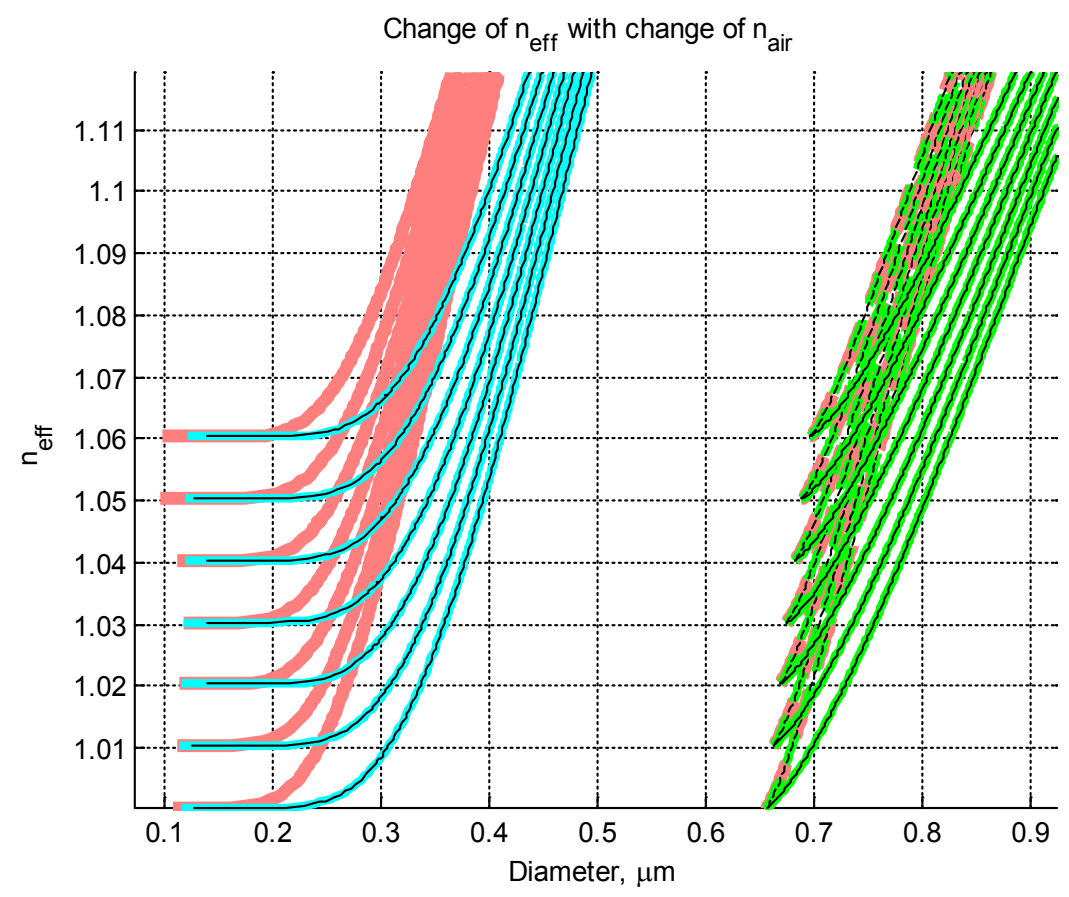

b)

Figure 11.

a) Change of effective refractive index with diameter, b) zoomed part of a). 
Figure 11 shows change of the effective refractive index with the diameter of fiber. The comparison is made for twolayer and three-layer cases (Karapetyan, 2011). Air's refractive index is simulated from 1.000293 to 1.07 . Our results show that $6.968 \%$ change in the refractive index, $\mathrm{n}_{\text {eff }}$ is changed for $6 \%$ (i.e. at $0.1 \mu \mathrm{m})$. In this simulation, the change of the refractive index of $7 \%$ was not shown fatal, because no mode was lost. The modes before and under environmental influence present in the optic system are Erdogan cladding modes (3-layer case) (Erdogan, 1997; Erdogan, 2000; Karapetyan, 2011). These modes are available only for cladding-guided modes, where the effective refractive index is smaller than cladding refractive index. The three layer stucture can be approximated with the two-layer one in the regions where the third layer can be neglected.

\section{CONCLUSIONS}

In this study we could not find evidence of mode loss due to environmental impact. However, it is evident that the environmental influences contribute to the variations in the refractive index. In the three-layer system, environmental parameters are directly involved in light wave guidance. In the two-layer system, jacket annulets many environmental influences, but it is obvious that i.e. temperature variation could lead to refractive index change. Temperature variations are realistic aboard ships.

Further work should include the development of models, which include interaction of as much as possible parameters in dependent manner, which is the opposite of the presented independent manner. Furthermore, the theoretical model should be improved by including a correction for salinity, i.e. through density.

\section{REFERENCES}

Airborne Salinity, available at:

http://www.galvinfo.com:8080/zclp/definition/airborne_salinity.html, [accessed 20 January 2015.].

Belanov, A. S., (1976), Propagation of normal modes in multilayer optical waveguides I. Component fields and dispersion characteristics, Soviet Journal of Quantum Electronics, 6(1), pp. 43.

http://dx.doi.org/10.1070/QE1976v006n01ABEH010808

Ciddor, P. E., (1996), Refractive index of air: new equations for the visible and near infrared, Applied Optics, 35(9), pp. 1566-1573.,

http://dx.doi.org/10.1364/AO.35.001566

Edlen, B., (1966), The refractive index of air, Metrologia 2, pp. 71-80., http://dx.doi.org/10.1088/0026-1394/2/2/002

Edlen, B., (1953), The dispersion of standard air, Journal of the Optical Society of America, 43(5), pp. 339-344.,

http://dx.doi.org/10.1364/JOSA.43.000339

Erdogan, T., (1997), Cladding-mode resonances in short- and long-period fiber grating filters, Journal of Optical Society of America A, 14(8), pp. 1760-1773.,
http://dx.doi.org/10.1364/JOSAA.14.001760

Erdogan, T., (2000), Cladding-mode resonances in short- and long-period fiber grating filters: errata, Journal of Optical Society of America A, 17(11), pp. 2113-2113., http://dx.doi.org/10.1364/JOSAA.17.002113

Frederickson, P. A., Davidson, K. L., Zeisse, C. R. and Bendall, C. S., (2000), Estimating the Refractive Index Structure Parameter over the Ocean Using Bulk Methods, Journal of Applied Meteorology, 39, pp. 1770-1783.,

http://dx.doi.org/10.1175/1520-0450-39.10.1770

Friehe, C. A., La Rue, J. C., Champagne, F. H., Gibson, C. H. and Dreyer, G. F., (1975), Effects of Temperature and Humidity Fluctuations on the Optical Refractive Index in the Marine Boundary Layer, Journal of the Optical Society of America, 65(12), pp. 1502-1511.,

http://dx.doi.org/10.1364/JOSA.65.001502

Galindez, C., Lomer, M., Rodriguez-Cobo, L. and Lopez-Higuera, J. M., (2012), Influence of the refractive index of liquids in the speckle pattern of multimode fibers, Proc. V International Conference on Speckle Metrology, Proc. of SPIE, vol. 8413, pp. 84131Q-1 - 84131Q-6.

Gantt, B. and Meskhidze, N., (2013), The Physical and Chemical Characteristics of Marine Primary Organic Aerosol: a Review, Atmospheric Chemistry and Physics, 13, pp. 3979-3996.

http://dx.doi.org/10.5194/acp-13-3979-2013

Gupta, R., Burnett, J. H., Griesmann, U. and Walhout, M., (1998), Absolute refractive indices and thermal coefficients of fused silica and calcium fluoride near $193 \mathrm{~nm}$, Applied Optics, 37(25), pp. 5964-5968.,

http://dx.doi.org/10.1364/A0.37.005964

Helhel, S., Colak, B. and Özen, S., (2007), Measurement of Dielectric constant of Thin Leaves by Moisture Content at $4 \mathrm{~mm}$ Band, Progress In Electromagnetics Research Letters, 7, pp. 183-191.,

http://dx.doi.org/10.2528/PIERL09021605

ISO 9225, (1992), Corrosion of Metals and Alloys-Corrosivity of AtmospheresMeasurement of Pollution, ISO, Geneva, Switzerland.

Jin, Z. and Stamnes, K., (1994), Radiative Transfer in Nonuniformly Refracting Layered Media: Atmosphere-Ocean System, Applied Optics, 33(3), pp. 431-442., http://dx.doi.org/10.1364/AO.33.000431

Kaiser, D. R., Reinert, D. J., Reichert, J. M. and Minella, J. P. G., (2010), Dielectric Constant Obtained from TDR and Volumetric Moisture of Soils in Southern Brazil, Revista Brasileria de Ciência do Solo, 34(3), pp. 649-658., http://dx.doi.org/10.1590/S0100-06832010000300006

Karapetyan, K., (2011), Optical Fibre Toolbox, available at: http://www.mathworks.com/matlabcentral/fileexchange/27819-optical-fibretoolbox, [accessed 11 January 2015.].

Kasap, S. O., (2006), Principles of Electronic Materials and Devices, 3rd ed., New York: McGraw Hill.

Kulenović, Z., Vujović, I. and Kežić, S. V., (2014), Simulation of Important Factors' Impact in the Choice of Dielectric Material for Marine Applications, Proc. International Maritime Science Conference, Solin, Croatia, April 28-29, pp. 261-270., availabe at: http://www.pfst.hr/imsc/archive/2014/IMSC2014_proceedings.pdf, [accessed 8 January 2015.].

Leviton, D. B. and Frey, B. J., (2006), Temperature-dependent absolute refractive index measurements of synthetic fused silica, available at: http://arxiv.org/ftp/arxiv/papers/0805/0805.0091.pdf, [accessed 20 December 2014.].,

http://dx.doi.org/10.1117/12.672853 
Monerie, M., (1982), Propagation in doubly clad single-mode fibers, IEEE Journal of Quantum Electronics, 18(4), pp. 535 - 542.,

http://dx.doi.org/10.1109/JQE.1982.1071586

Review of Maritime Transport 2013, (2013), UNCTAD, New York.

Silans, T.P., Maurin, I., Segundo, P. C. S., Saltiel, S., Gorza, M. P., Ducloy, M., Bloch, D., Meneses, D. S. and Echegut, P., (2009), Temperature dependence of the dielectric permittivity of $\mathrm{CaF} 2, \mathrm{BaF} 2$ and Al2O3: Application to the prediction of a temperature dependent van der Waals surface interaction exerted onto a neighbouring Cs (8P3/2) atom, Journal of Physics: Condensed Matter, 21, 255902.,

http://dx.doi.org/10.1088/0953-8984/21/25/255902

Slamova, K., Glaser, R., Schill, C., Wiesmeier, S. and Köhl, M., (2012), Mapping Atmospheric Corrosion in Coastal Regions: Methods and Results, Journal of Photonics for Energy, 2, pp. 022003-1 - 022003-11.,

http://dx.doi.org/10.1117/1.JPE.2.022003

Stone, J. A. and Zimmerman, J. H., (2004a), Index of Refraction of Air, Engineering Metrology Toolbox, available at:

http://emtoolbox.nist.gov/Wavelength/Documentation.asp, [accessed 17 January 2015.].

Stone, J. A. and Zimmerman, J. H., (2004b), Refractive Index of Air Calculator, available at: http://emtoolbox.nist.gov/Publications/NBSIR73-232.asp, [accessed 17 January 2015.].

Thayer, G. D., (1974), An Improved Equation for the Radio Refractive Index of Air, Radio Science, 9(10), pp. 803-807., http://dx.doi.org/10.1029/RS009i010p00803

Tsao, C. Y. H., Payne, D. N. and Gambling, W. A., (1989), Modal characteristics of three-layered optical fiber waveguides: a modified approach, Journal of the Optical Society of America - A, 6(4), pp. 555-563., http://dx.doi.org/10.1364/JOSAA.6.000555

Unknown, Seawater Density \& Salinity, (2002), available at: http://www.msc.ucla.edu/oceanglobe/pdf/densitysalinity/densityintro.pdf, [accessed 12 February 2015.]

Vujović, I., Kuzmanić, I. and Kulenović, Z., (2014a), Dielectric Materials' Selection for Marine Applications, Saarbrücken: Lambert Academic Publishing.

Vujović, I., Kulenović, Z. and Kežić, S. V., (2014b), Proposal of New Method for Dielectric Materials Selection in Ship System Applications, Naše more (Precious Sea), 61(1-2), pp. 28-32., available at: http://hrcak.srce.hr/file/179823

Waxler, R. M. and G. W. Cleek, (1973), The Effect of Temperature and Pressure on the Refractive Index of Some Oxide Glasses, Journal of Research of the National Bureau of Standards - A. Physics and Chemistry, 77A(6), pp. 755-763., http://dx.doi.org/10.6028/jres.077A.046

Waxler, R. M. and Cleek, G. W., (1971), Refractive Indices of Fused Silica at Low Temperatures, Journal of Research of the National Bureau of Standards-A. Physics and Chemistry, 75A(4), pp. 279-281.,

http://dx.doi.org/10.6028/jres.075A.026

Zi-jia Zhang and Wen-kang Shi, (2005), Eigenvalue and field equations of threelayered uniaxial fibers and their applications to the characteristics of long-period fiber gratings with applied axial strain, Journal of the Optical Society of America - A, 22(11), pp. 2516-2526.,

http://dx.doi.org/10.1364/JOSAA.22.002516 